Journal of Engineering and Applied Sciences 7 (3): 238-245, 2012

ISSN: 1816-949X

(C) Medwell Journals, 2012

\title{
Preparation Before Commercialization: A Case Study
}

\author{
${ }^{1,2}$ Mohammad Syuhaimi Ab-Rahman, ${ }^{1,}{ }^{2}$ Hadiguna, ${ }^{2}$ Hazwan Harun, \\ ${ }^{1}$ Syuhada Zalmi and ${ }^{2}$ Kasmiran Jumari \\ ${ }^{1}$ Research Advancement Strategic and Planning (RASP), \\ ${ }^{2}$ Spectrum Technology Research Group (SPECTECH), \\ Department of Electrical, Electronic and System Engineering, \\ Faculty of Engineering and Built Environment, \\ Universiti Kebangsaan Malaysia, 43600 UKM Bangi, Selangor, Malaysia
}

\begin{abstract}
Product commercialization of higher education is one of a national asset and it should be well developed and systematic. Through the policy of commercialization, it has given a new chapter to the researcher in terms of incentives and royalty percentage. Most of the research is able to produce prototypes and intellectual property but not all succeeded in making a product. Therefore, it is the responsibility of researchers and institutions to bring the prototype to the next level for marketing to local and overseas markets. This study proposes measures that can be carried out by researchers led to the commercialization of products. There are three assessments done, comparative aalysis, professional and market assessment. Two leading companies in the country were invited to perform this assessment. As a result of organized activities allow researchers to get a clear picture about the market potential of intellectual property. In addition, the responses and ratings provided by these companies can also be used to apply for commercialization funds offered by any financial institution or a grant or directly commercialize the products.
\end{abstract}

Key words: Product commercialization, intellectual property, comparative analysis, professional assessment, market assessment, Malaysia

\section{INTRODUCTION}

Innovation is fundamental to the growth and development of a country. It is a catalyst that will determine the shape and speed the country to become a developed nation. For Malaysia, it is the core in the transition to the economy led by technology in the future where it is important for maintaining competitiveness. The changes occurring today require the government and industry to put innovation and creativity as a key factor in ensuring that the shift to knowledge-based economy can be achieved.

In this regard, countries should strengthen through the stimulation of innovation and forge new ideas and inspiration, expands the existing talent, exploit the creativity and inventive ability of the country's human capital to the maximum level. In addition, the industry must move quickly to produce more value-added products and efficient in meeting market requirements. A proactive and integrated approach is essential to fulfill the needs of Vision 2020 and enable Malaysia to position itself strategically in line with other more developed countries and influential. Commercialization is the process of developing market and producing and delivery products or services for sale whether by originating party or by others.

The level of intellectual property commercialization in Malaysia is still low with the number of products has been commercialized from the Research and Development (R\&D) findings is carried out only 3.4\% from the funds allocated. Ministry of Science, Technology and Innovation (MOSTI) in the ninth Malaysia Plan is responsible for managing $\mathrm{R} \& \mathrm{D}$ funds of $\mathrm{RM} 27$ billion for the fund's portfolio of innovation science and technology. In an effort to promote the commercialization, the government has formulated the policies of intellectual property commercialization of $R \& D$ where the recipient of government funds would be an ideal owner for the

Corresponding Author: Mohammad Syuhaimi Ab-Rahman, Research Advancement Strategic and Planning (RASP), Department of Electrical, Electronic and System Engineering, Faculty of Engineering and Built Environment, Universiti Kebangsaan Malaysia, 43600 UKM Bangi, Selangor, Malaysia 
resulting intellectual property. The government also provides an incentive of RM15,500 for researchers who are able to produce patents. They will get $80 \%$ royalties from the commercialization of the results. In 2009, a total of 270 registered patents in MyIPO.

One of the Key Performance Index (KPI), the ministry is to increase the number of patents at a rate of $10 \%$ this year. Research based innovation can lead the improvements to existing products or processes other than a new production based on existing theory. Research in this category is one of the branches of research applications by:

- Production of creative and innovative using the existing theory

- New discoveries to improve products or processes

Commercialization is the basis of a country's competitiveness. Quality of life depends on the creativity of its people. The pride of a nation can be improved through innovative capabilities. Sources of the new economy can be explored with the generation of new knowledge and technology upgrading through innovation and creativity. Steps towards the commercialization of a project started by triggering new ideas shown by the results based on innovation.

The application/innovation study is a research towards the formation or development of an innovation results. The research covers the process of planning,implementing research, analyze, document and develop engineering prototypes, protect the idea (the idea of patents). Commercialization processes include the following:
- The 1st stage of assessment (screening product)

- Potential product undergoes a market need analysis the idea of patent before market survey if the product is not covered

- Positive results from the market need analysis allows the development of commercial prototypes (with enhancement features after getting feedback from the target customers)

- Testing of product

- Economic considerations; mass production, end user vs. manufacturer considerations, entrepreneurship, funding

- Ownership, outright vs. royalty

Figure 1 shows the strategies to promote commercialization. It involves all levels from national leaders, institutional management, head of marketing and finally the researchers. In addition, the involvement of the industry is also important in catalyzing the development of commercialization in the country.

This study proposes three components that need to be done before the commercialization process. Three components are:

- Market survey/comparative analysis

- Professional assessment

- Market assessment

From the responses obtained from all three of these activities, it gives a clear picture of the market potential of intellectual property. This strategy is suitable to be applied in research and innovation at the university for the purpose of commercialization of research results because not all universities have complete equipment and facilities. Through the proposed strategy can also be used

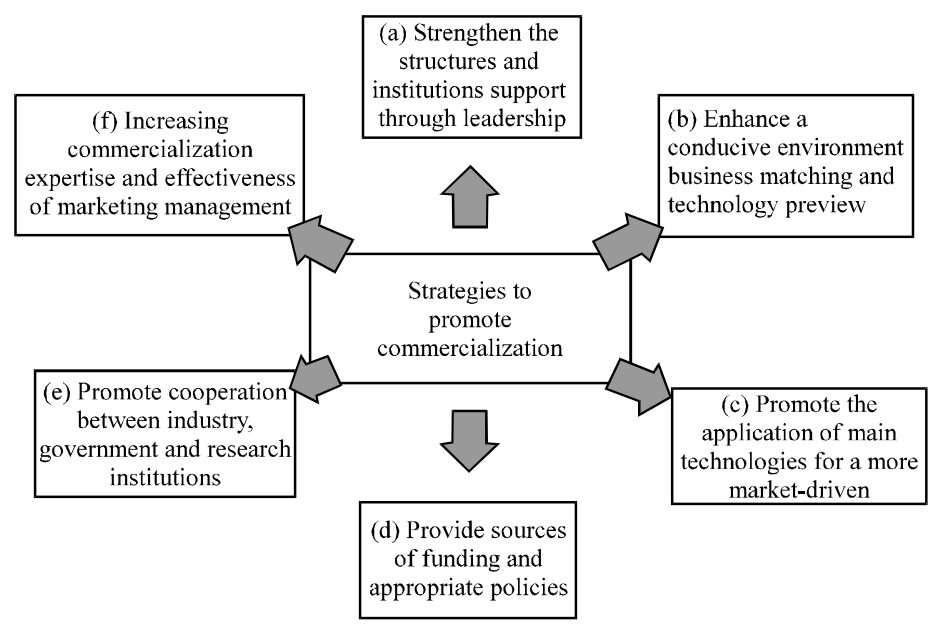

Fig. 1: Strategies to encourage the commercialization from higher education institution and research institute 
as the measure of the intellectual property and received the response assessment can be used to upgrade the product to be produced. In addition, it can also be strength to win the funding applications for future commercialization.

Product description: Here researchers utilized fused splitters, three number LEDs as a source, three number photo detectors at receiver-end and low-cost filters to develop a whole system of Wavelength Division Multiplexing-Plastic Optical Fiber (WDM-POF) for in-vehicle entertainment network application system (Ab-Rahman et al., 2009a). The most important aspect that plays an important role to transmit three different signals represented by different color on transmitter devices is the filter which is placed between the low cost splitter and the receiver-end.

In this research, three different LED were utilized; red LED $(650 \mathrm{~nm})$ transmit an internet line through LAN connection and green LED $(520 \mathrm{~nm})$ to deliver a high quality video signal to be displayed on a monitor screen and blue LED (470 $\mathrm{nm}$ ) represents an audio signals which distributed inside the vehicle as shown in Fig. 2. Only $5 \mathrm{~V}$ DC is used to drive LED current that can be further modulated with signals (video, audio information) to distribute amongst the passengers in the car. Figure 3 shows the products ( $\mathrm{POF}$ demultiplexer) that are used in high capacity WDM-POF network for in-vehicle entertainment and communication system. Through a POF Optical Splitter $1 \times 3$ and $1 \times 4$ cascad device allows $1 \times 12$ devices designed (Ab-Rahman et al., 2009c; Safnal et al., 2009). Recent communication system over POF requires more bandwidth and therefore, the Wavelength Division Multiplexing (WDM) System is the solution that allows the transmission of information over more than just a single wavelength (color) and thus, greatly increases the POF's bandwidth (Ab-Rahman et al., 2010).

WDM is a technique that multiple signals are carried together as separate wavelengths (color) of light in a multiplexed signal as shown is Fig. 4, Wavelength Division Multiplexer (WDM) is the first passive device required in WDM-POF System and it functions to combine optical signals from multiple different single-wavelength end devices onto a single fiber (Ab-Rahman et al., 2009b). CAN is a multi-master broadcast serial bus standard for connecting Electronic Control Units (ECUs). Each node is able to send and receive messages but not simultaneously. A message consists primarily of an id (identifier) which represents the priority of the message and up to 8 data bytes.

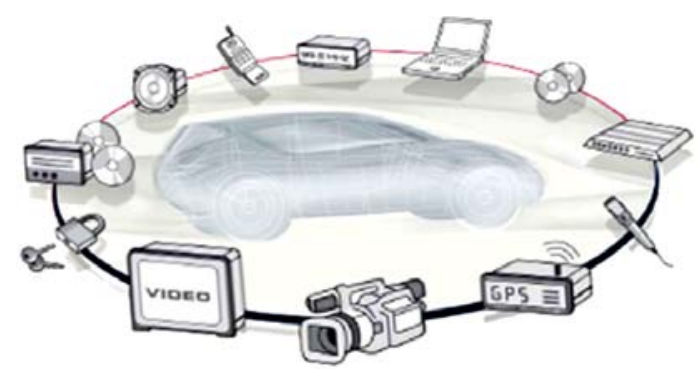

Fig. 2: Eco-friendly WDM-POF networking seems to be the future technology to distribute the entertainment data with high speed and high capacity solution

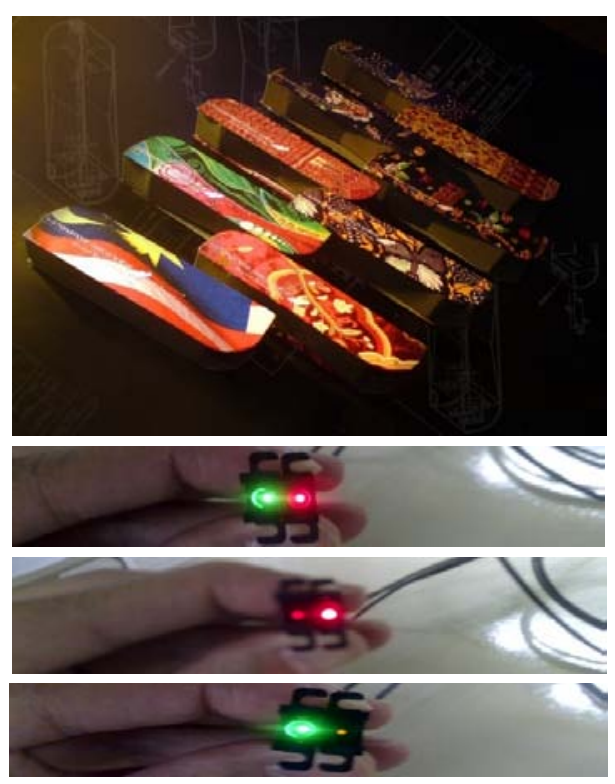

Fig. 3: Prototype of the green technology handmade $1 \times \mathrm{N}$ POF demultiplexer. The device is used to split the signal to different frequency (color) which representing video and data signal (Patent Application No: PI2010700001)

It is transmitted serially onto the bus. This signal pattern is encoded in Non-Return-to-Zero (NRZ) and is sensed by all nodes. The devices that are connected by a CAN network are typically sensors, actuators and other control devices. These devices are not connected directly to the bus but through a host processor and a CAN controller. A modern automobile may have as many as 70 Electronic Control Units (ECU) for various subsystems. Typically, the biggest processor is the engine control unit (also Engine Control Module/ECM or Power train Control Module/PCM in automobiles), others are used for transmission, airbasgs, Antilock Braking/ABS, cruise 


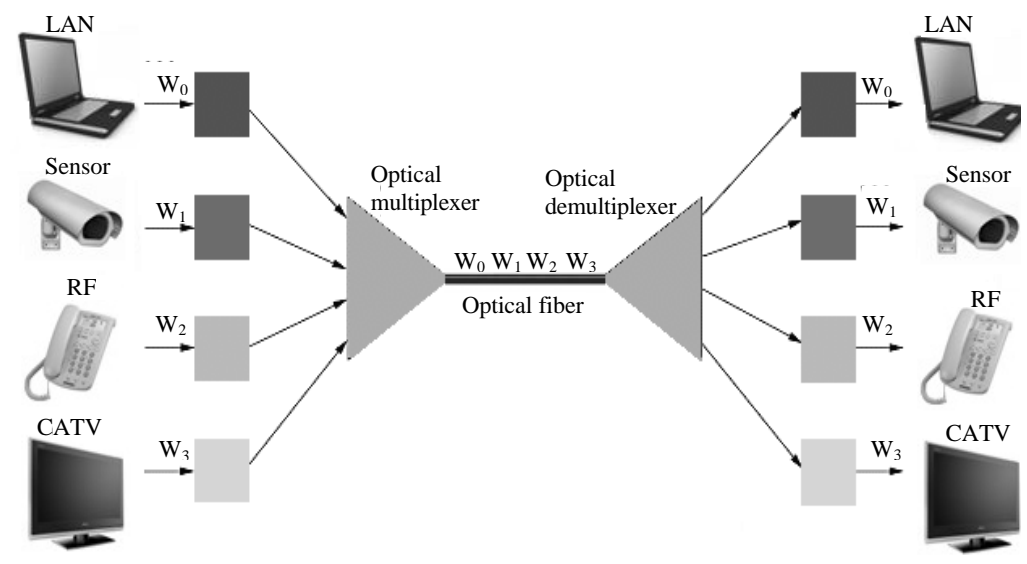

Fig. 4: Wavelength Division Multiplex (WDM) with an optical multiplexer and demultiplexer that have potential are used in car and home network

control, Electric Power Steering/EPS, audio systems, windows, doors, mirror adjustment, etc. Some of these form independent subsystems but communications among others are essential. A subsystem may need to control actuators or receive feedback from sensors. The CAN standard was devised to fill this need.

The CAN bus may be used in vehicles to connect engine control unit and transmission or (on a different bus) to connect the door locks, climate control, seat control, etc. Today, the CAN bus is also used as a fieldbus in general automation environments, primarily due to the low cost of some CAN controllers and processors. Old in-vehicle network protocols like D2B, LIN and CAN are combining or replacing by FlexRay, Ethernet, MOST Systems.

These new technologies need to be at least as reliable as the systems they are replacing. Moreover, regulations requiring emissions diagnostics together with the ever increasing in car electronics further increase the number of applications relying on communications.

Different automotive applications have different requirements on the networking capabilities, resulting in a number of networking protocols. Automotive subsystems such as steering and braking will be replaced by communication networks (wires), Electronic Control Units (ECUs), electric/electromagnetic sensors and actuators.

An automotive system consisting of several subsystems with a total of up to 110 ECUs that together might have to distribute $>2500$ variables and signals. This makes the automotive system complex in many ways including networking. POF communication has also been proposed for use in the placement of the aborigines as a

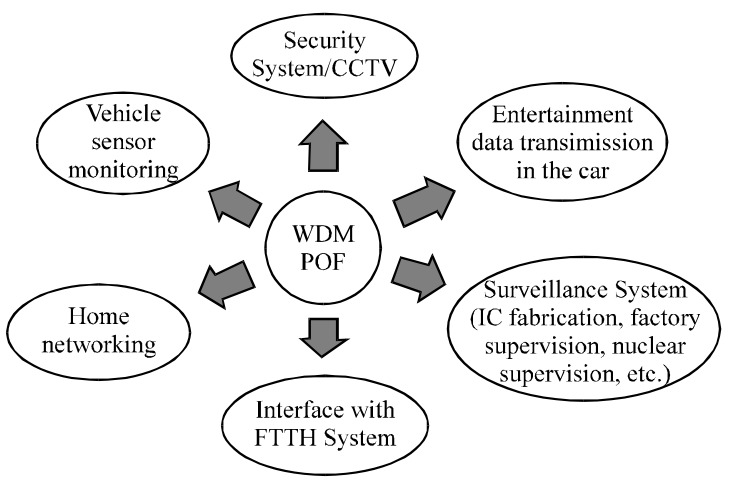

Fig. 5: Applications of POF-WDM Communication System

communications medium that connects homes, community centers, schools and others with the outside world. Because of the easy care and maintenance make this technology suitable to be used in remote and difficult to access areas (Ab-Rahman et al., 2011b). Therefore, this technology not only generates funding for the country but also ensure that indigenous socio-economic development in Malaysia.

Commercialization strategy: Figure 5 shows a flowchart for the process of pre-commercial purposes. It started by conducting comparative between the products developed with several existing and identified products in markets. Two products were selected and comparative analysis is shown in Table 1.

The results obtained show Spectech prototype has comparable features such as insertion loss and excess loss and has the advantage of uniformity and production costs. Professional evaluation carried out using the 
Table 1: Analysis of comparison between products Spectech with existing products on the market

\begin{tabular}{lll}
\hline Parameters & $\begin{array}{l}\text { Low cost fused } \\
\text { tapper (Spectech) }\end{array}$ & $\begin{array}{l}\text { Industrial fiber optic } \\
\text { incorporation }\end{array}$ \\
\hline Insertion loss & $4-8 \mathrm{~dB}$ & $0.2-7.0 \mathrm{~dB}$ \\
Excess loss & $0.7-5.8 \mathrm{~dB}$ & $<1.5 \mathrm{~dB}$ \\
Uniformity & $1 \mathrm{~dB}$ & $6.28 \mathrm{~dB}$ \\
$\begin{array}{l}\text { (P2P Difference) } \\
\text { Cost }\end{array}$ & Low & High \\
Expansion & Yes (Demultiplexer) & No \\
\hline
\end{tabular}

services of Prominent Line Ltd., for technical evaluation of products. The response obtained requires us to conduct several more tests such as strain and tension so that the device can be expanded to wider applications. Normally, the facilities available in universities are limited and there may be some important parameters that are not measured. Any defects in the characterization that was carried out can be executed through professional evaluation. The company also offers to organize a workshop to promote intellectual property are to invite prospective entrepreneurs in this field. The aim is to get the response and comments about this product competitive in the market.

If there are any interest, the agreement will be made either in the form of an intellectual property purchase or license for production. Market assessment is to assess the marketability of this intellectual property. Company's existing operators in this area called and asked to evaluate the intellectual property in terms of feasibility and assembly in Malaysia.

Feedbacks and comments from the evaluators is very useful to improve the quality of the product will be produced later. Interest by the company on intellectual property (particularly in the existing network installation) will also be asked and if the positive response given the commercialization process will be carried to the next level (Fig. 6).

Market survey and comparative analysis: Customers are the foundation of any successful business. An effective market research survey will show the customer needs and desires, determines whether your product or service will meet expectations and assists with the planning process. Market surveys are conducted either in-house by the company or through a marketing research agency. Market surveys are extremely important because companies learn what their customers like and dislike about their products and services.

That way, companies can better meet their customers' demands. Another form of market survey is conducting comparative analysis. Here, researchers compare 1-1 the similar product from the other companies. Characteristics and performance of each product will be compared.

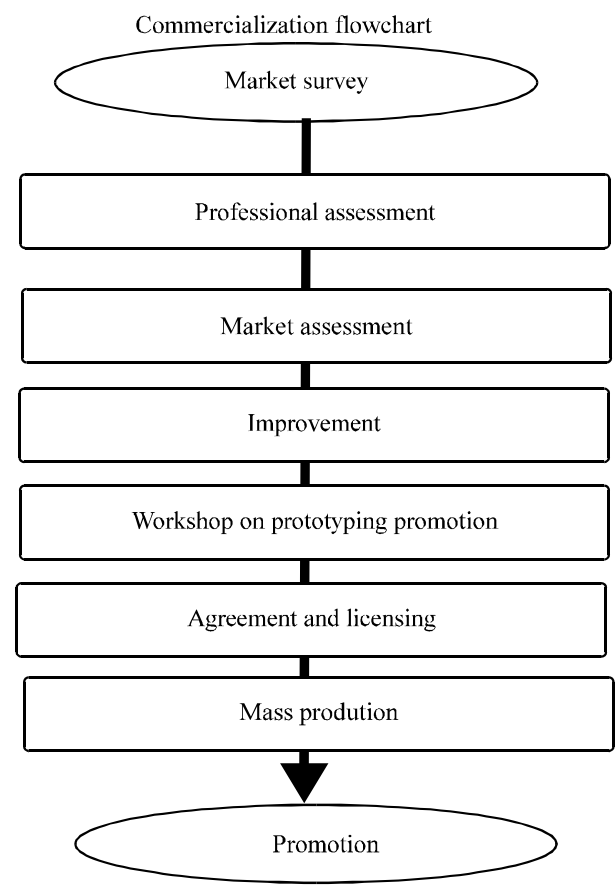

Fig. 6: Process flowchart of the proposed pre-commercial

Comparison is important in determining the advantages and disadvantages of products we produce. Figure 7 shows an example comparison of performance to assess the parameters of splitting ratio for both products. The products are also observed compared with the 1 st generation.

In addition, the analysis of products usage in current industry also needs to be done to identify the opportunities and market for the products later. More functions and features that may be offered by a larger application of products that can be attributed to the industry and ultimately the larger the market size of this product later.

From the observations, $\mathrm{POF}$ splitter device has a high uniformity of $\mathrm{POF}$ compared to most commercial devices (Ab-Rahman et al., 2011a). With this feature, POF splitter device can be developed as demultiplexer device. For now, demultiplexer device is still not available in current market.

Market evaluation: Market evaluation is critical in assessing the potential of a product in the eyes of the industry involved. The professional results might also discuss competitors and their current market shares, depending on the invention (White, 2002) (Fig. 8). That is why, we invite a leading telecommunications company to evaluate the products produced in this laboratory. The assessment is in terms of improvement of existing systems 


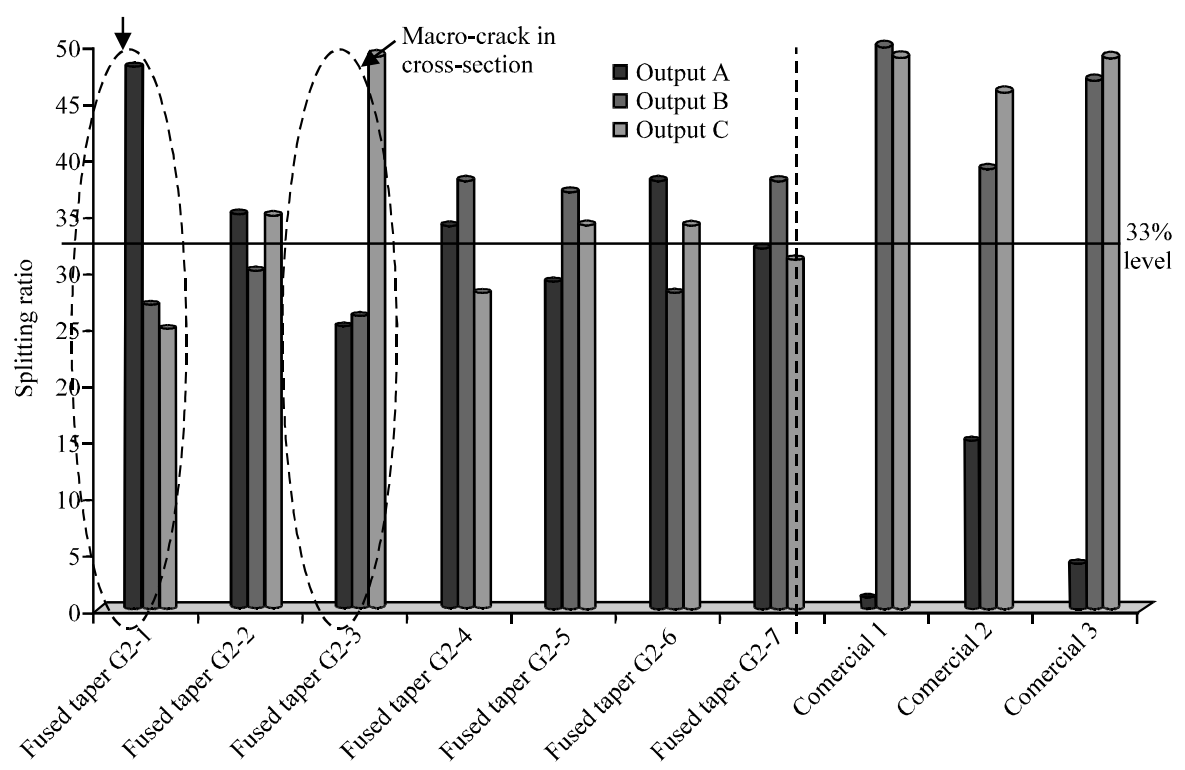

Fig. 7: Histogram of splitting ratio for the 2nd generation of $\mathrm{LFT}^{\mathrm{TM}}$ splitter and commercial splitter; the 2nd generation of $\mathrm{LFT}^{\mathrm{TM}}$ splitter are better

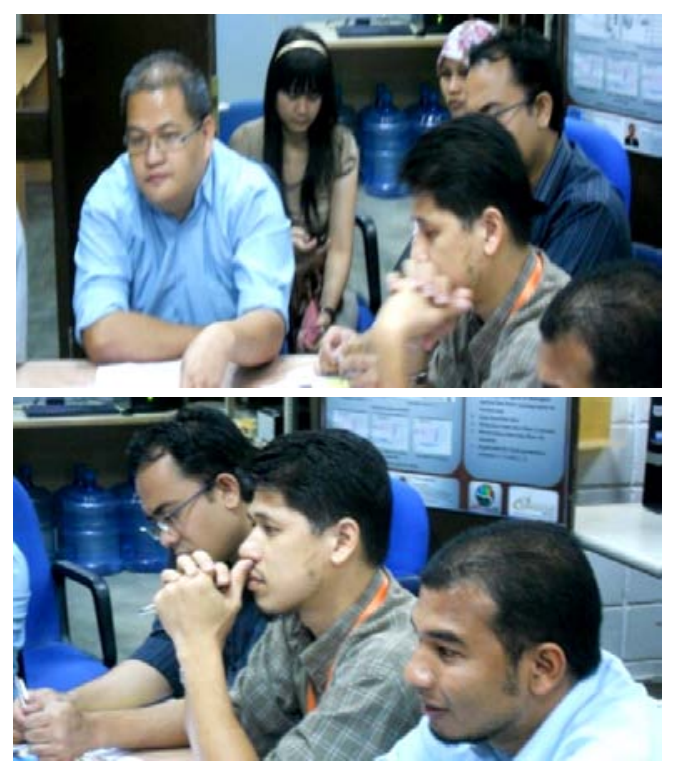

Fig. 8: Evaluator from the industry are invited to market assessment

with the introduction of this product to a system developed at the company. The marketability of products for the local and foreign level and also acceptance of this product are accessed by the company. This evaluation form is shown in Fig. 9. Among other questions that asked were about the suitability of this product in the Malaysian market and it is still relevant for the next 5 years.

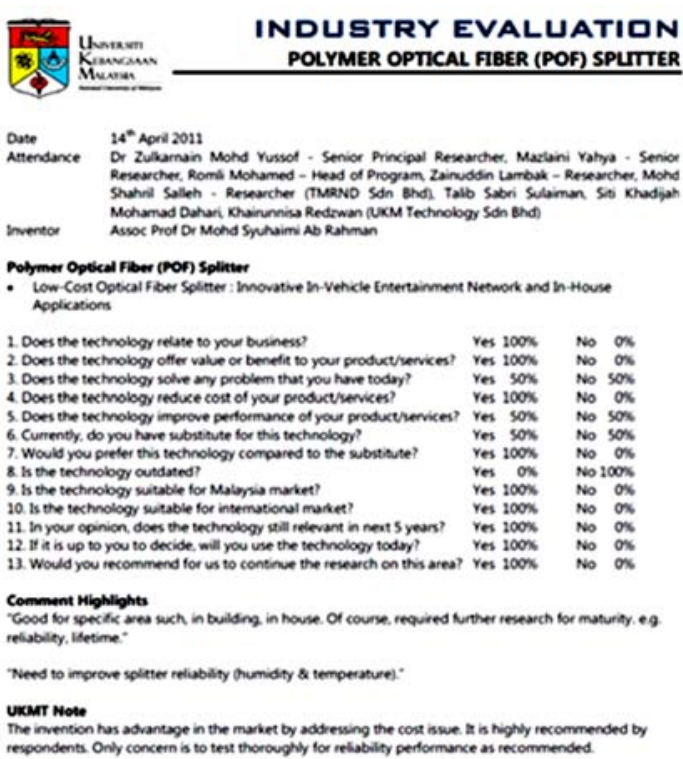

Fig. 9: The evaluation form used in the market assessment

Professional evaluation: Professional evaluation carried out by inviting companies to research labs and made presentations on intellectual property. Normally, it would be accompanied by university representatives who manage university intellectual properties. A technical report submitted to the representative of the company for analysis.

Based on analysis of reports that have been returned, there are some important characterization parameters to 

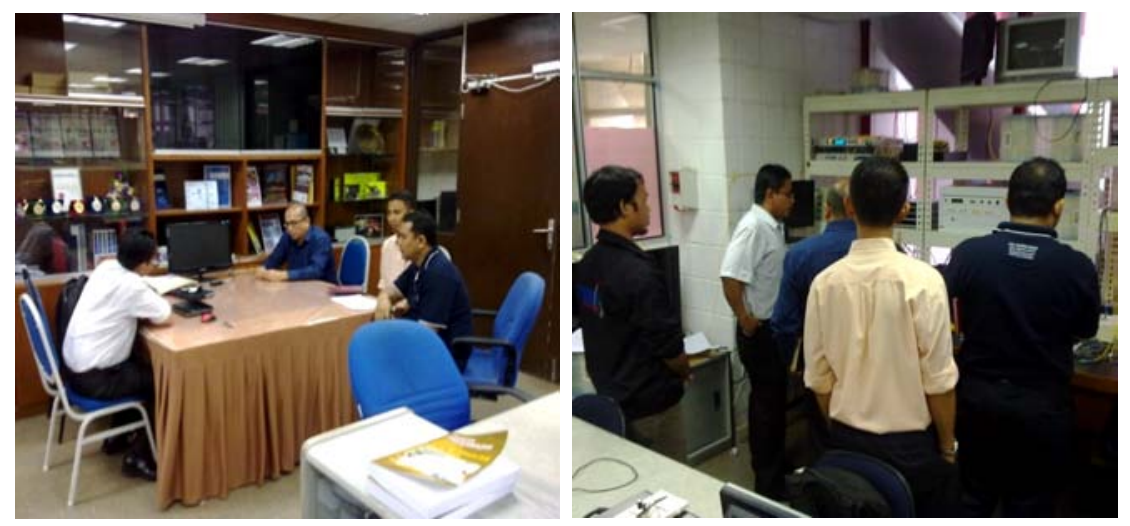

Fig. 10: Prominent Line Ltd. visit the Spectech Laboratory

Prominent Line Sdn Bhd recommends that:

Researcher has to maintain the stability especially the insertion loss of the handmade splitter itself at least $<10 \mathrm{~dB}$ for every port for $1 \times \mathrm{N}$ handmade splitter

Low-loss connector is needed for connection between optical transmitter and POF

Researcher has to maintain the reliability of the handmade splitter together with the wavelength division multiplexing system to perform a data transmission process at least $100 \mathrm{~m}$ transmission distance to make sure that the entire system are appropriate to be integrated into automotive system and home networking

Housing of the prototype need to be improved, in term of weight of the casing, material of the housing need to replace by plastic or aluminium which is lighter than the metal itself

Researcher has to provide a better mechanical-based tools to replace a common twisting and pulling method or instead of using hand to make sure that the performance of the handmade splitter are constant

The length of the tapered area of handmade splitter must be shortened to make sure that the housing/casing are smaller than before

Researcher has to find/buy a latest (polymer) optical fiber-based spectrum analy zer and high resolution optical power meter to gain a better measurement result and better specification

Researcher has to compare the efficiency of the handmade splitter to other POF-based splitting method such as moulding-based splitter, prism, etc.

The project have to provide a tuneable bumer/heater to find the best level of temperature for fusion process, beside researcher can conduct a further study on effect of heating process to a fused splitter

The project need to improve the testbed and the whole networking to be exposed to industrial/partner to convince them as much as network/system can be integrated using handmade splitter together with wavelength division multiplexing-based technology

The crosstalk and signal-to-ratio of the handmade splitter need to improved and lies between -20 to $-30 \mathrm{~dB}$

Researcher has to provide some samples to be distribute so some company in a small scale to make sure that they will provide a feedback about the ease of use of the handmade splitter in their system, especially for some system related to small world networking such as automotive, fiber to the home, intemet service provider, home networking

Fig. 11: Professional assessment report by Prominent Line Ltd.

implement if we are intend to commercialize the intellectual property internationally and there are several suggestions recorded for improvement.

This assessment is important to get expert advice on intellectual property technically in order to compete at international level (Fig. 10).
Special visit from the department of prime minister: This intellectual property has been selected among the 10 prototype will be evaluated by the Department of Prime Minister to be commercialized. It is an opportunity that should be taken to bring products for further research (Fig. 11 and 12). 


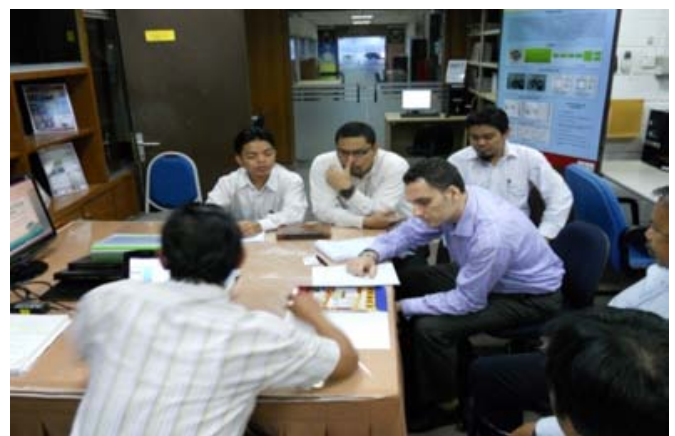

Fig. 12: Discussion between UKM-Spectech and representatives from the Department of Prime Minister

\section{CONCLUSION}

Using the assessment report prepared by the evaluator allows the project have a high opportunity of research grant applications such as the Prototype Research Grant Scheme (PRGS) innovation, Cradle fund and others. The research was enough to convince the providers of grants for which this project has the potential to be commercialized with improved systems and plenty of preparation. This study has managed to propose some evaluation may be made before commercialization possible.

\section{REFERENCES}

Ab-Rahman, M.S., H. Guna and M.H. Harun, 2009a. Realization of an economical $1 \times 3$ fused-taper-twisted polymer optical fiber splitters for small world communication. Malaysian J. Sci., 28: 289-297.
Ab-Rahman, M.S., H. Guna, H. Harun and K. Jumari, 2011a. The importance of uniformity to demultiplexer device fabrication for POF based small world communication. Adv. Nat. Applied Sci., 5: 166-170.

Ab-Rahman, M.S., H. Guna, H. Harun, I.H. Kaharuddin and $\mathrm{K}$. Jumari, $201 \mathrm{lb}$. Implementation of maintainable and extendable green communication technology to deep rural area-indigenous people development roposal. J. Applied Sci. Res., 7: 885-890.

Ab-Rahman, M.S., H. Guna, M.H. Harun and K. Jumari, 2010. Fabrikasi dan pencirian pencerai optik $1 \times 12$ Buatan tangan berasaskan Gentian optik polimer diperbuat daripada polimetil metakrilat. Sains Malaysiana, 39: 459-466.

Ab-Rahman, M.S., H. Guna, M.H. Harun, M.D. Zan and K. Jumari, 2009b. Bidirectional optical power measurement for high performance polymer optical fiber-based splitter for home networking. Aust. J. Basic Applied Sci., 3: 1661-1669.

Ab-Rahman, M.S., H. Guna, M.H. Harun, M.D. Zan and K. Jumari, 2009c. Home-made optical 1x12 fused-tapertwisted polymer optical fiber splitters for small world communication. Res. J. Applied Sci. (In Press)

Safnal, M.H.G., M.S. Ab-Rahman and M.H. Harun, 2009. Fabrication and characterization of optical $1 \times 12$ fused-taper-twisted polymer optical fiber splitters. J. Opt. Commun., 30: 16-19.

White, J.E., 2002. Will it sell? How to determine if your invention is profitably marketable (Before wasting money on a patent). http://www.willitsell.com/gete val.asp. 